\title{
Clinical and scientific progress related to the interface between cardiology and psychology: lessons learned from 35 years of experience at the Thoraxcenter of the Erasmus Medical Center in Rotterdam
}

\author{
R. A. M. Erdman • S. S. Pedersen
}

Published online: 1 September 2011

(C) The Author(s) 2011. This article is published with open access at Springerlink.com

\begin{abstract}
In November 1975, as the first in the Netherlands, a full-time psychologist was employed at the Department of Cardiology of the Thoraxcenter of the Erasmus Medical Center. This innovative decision was consistent with a view to treat the patient as a whole rather than the heart as a single body part in need of repair, combined with the understanding that the heart and mind interact to affect health. The present selective review addresses the broad range of contributions of 35 years of psychology to clinical cardiology and cardiovascular research with a focus on research, teaching, psychological screening and patient care. The review ends with lessons to be learned and challenges for the future with respect to improving the care and management of patients with heart disease in order to enhance secondary prevention and the role of behavioural and psychological factors in this endeavour.
\end{abstract}

Keywords Behavioural factors · Cardiac psychology · Heart disease $\cdot$ Review

R. A. M. Erdman $(\bowtie) \cdot$ S. S. Pedersen

Department of Cardiology, Thoraxcenter,

Erasmus Medical Center,

PO Box 2040, 3000 CA, Rotterdam, the Netherlands

e-mail: r.erdman@erasmusmc.nl

R. A. M. Erdman

Department of Medical Psychology and Psychotherapy,

Erasmus Medical Center,

Rotterdam, the Netherlands

S. S. Pedersen

CoRPS - Center of Research on Psychology in Somatic diseases,

Tilburg University,

Tilburg, the Netherlands

\section{Introduction}

Clinical treatment and understanding of medicine has benefited greatly from the holistic view of the human body [1]. In cardiology, major advances have been made by examining the interactions between heart and mindthat is to say, cardiovascular medicine entails the art of medicine that understands disease as more than the sum of its parts-which in essence reflects the bio-psychosocial model that we know and use today. In November 1975, as the first in the Netherlands, Professor Paul G. Hugenholtz-Head of Cardiology at the Erasmus Medical Center (MC) in Rotterdam-elected to employ a full-time psychologist in the Department of Cardiology of the Thoraxcenter. This innovative decision was consistent with his view to treat the patient as a whole rather than the heart as a single body part in need of repair, combined with the understanding that the heart and mind interact to affect health. This integrative understanding of cardiology also gave rise to a practical need for a standardised self-report questionnaire that could provide cardiologists with quantifiable information about the psychological well-being of cardiac patients. As such, he could be considered a pioneer in behavioural cardiology. The present selective review addresses the broad range of contributions of 35 years of psychology to clinical cardiology and cardiovascular research in the Erasmus MC.

Cardiac psychology is the field of health psychology that identifies psychosocial risk factors for the development of cardiovascular illness and lifestyle changes that may help prevent and heal heart disease. In this selective review we address questions, including: Have patients profited? Have cardiologists, nurses on the 
ward, and other healthcare professionals managing cardiac patients benefited? Has it from a scientific point of view led to groundbreaking results? What are the lessons to be learned?

\section{Research in the field of cardiac psychology}

Over the past 35 years, research in the field of cardiac psychology at the Erasmus MC has been diverse. A selection of these investigations includes:

- Development and validation of psychological instruments for specific groups of heart patients [2-4].

- Information provision for patients undergoing cardiac surgery [5].

- Influence of early discharge of acute myocardial infarction (MI) patients on psychological morbidity [6].

- Psychosocial and physical functioning after cardiac rehabilitation [7].

- Psychological aspects of non-cardiac chest pain [8].

- Secondary prevention, multifactorial smoking cessation programme in cardiac patients [9].

- Psychosocial aspects in patients with congenital heart disease [10].

- Patient- and physician-related factors explaining the delay prior to admission among acute myocardial infarction patients [11].

- Effects of treating vital exhaustion in angioplasty patients on new coronary events [12].

- The role of personality as a determinant of quality of life in heart transplantation recipients [13].

- Web-based behavioural intervention in patients with an implantable cardioverter defibrillator (ICD) [14].

- Risk of chronic anxiety in patients with an ICD [15].

- Psychological morbidity and quality of life in patients with peripheral artery disease [16].

- Anxiety in partners of ICD patients and the role of personality, shocks and ICD indication [17, 18].

- Influence of personality and psychological distress on mortality in diverse groups of cardiac patients $[19,20]$.

Specific results deserve particular attention, since research in these patient groups is still ongoing at the Erasmus MC and because of their potential to influence patient care. These results relate to the impact of heart disease and treatment strategies on the emotional wellbeing and quality of life of patients, and the influence of psychological factors on morbidity and mortality. For this end, we have chosen to reflect on the results of patients with congenital heart disease and patients receiving stateof-the-art treatment, such as percutaneous coronary intervention (PCI) with drug-eluting stenting and ICD therapy. These last two patient groups have been the focus of cardiac psychology research in the Erasmus MC since 2001 and 2003 , respectively.

- A cohort study of 498 patients 15 years or younger at the time of surgical correction for congenital heart disease performed between 1968 and 1980 at the Erasmus MC and followed up for 10 years showed that these patients displayed scores in the psychological, deviant range compared with peers from a normative reference group (27\% versus $10 \%)$ [21]. A second follow-up of 362 patients 20-46 years postsurgery indicated that the congenital patients had measurable impairments in their level of education, occupation, and physical functioning. Predictors for long-term psychopathology were female gender, low exercise capacity, physical restrictions imposed by physicians, and the level of patient-perceived restrictions imposed by the scar following open heart surgery [22].

- In a consecutive cohort of 796 PCI patients treated with drug-eluting stenting between February 2005 and February 2006, 30.2\% patients were depressed 4 weeks post index event, as assessed with the 2-item Patient Health Questionnaire (PHQ-2). Depressed patients had an almost 2-fold increased risk of a non-fatal MI or mortality at a mean follow-up period of 1.4 years independent of their demographic and clinical risk profile. When stratifying analyses by gender, depressive symptoms were associated with a more than 2-fold increased risk of adverse clinical events in men but not in women [23].

- In a consecutive cohort of 371 patients implanted with an ICD between August 2003 and December 2008, the incidence of mortality was close to 3-fold higher in those with a distressed (Type D) personality and 2-fold higher in patients with high levels of ICD concerns adjusting for demographic and clinical characteristics including ICD shocks. Patients with clustering of both Type D personality and high levels of pre-implantation concerns (HR:3.86; 95\%CI:1.64-9.10) had a close to 4fold increased risk of mortality compared with patients with one or none of these risk markers in adjusted analysis. ICD shocks during the follow-up period was associated with a 3-fold risk of mortality [20].

Perhaps not surprisingly these results emphasise that despite state-of-the art treatment with new innovative techniques in clinical cardiology, after 35 years the psychological profile of the patient still matters. More importantly, psychological factors carry independent prognostic value, irrespective of and adjusting statistically for traditional biomedical risk factors, as also demonstrated by others (see Pedersen et al. for a further overview of the role of psychological factors in heart disease) [24]. Together with other research findings in the field of cardiac 
psychology [19, 23, 25-27], these results indicate that it is necessary to screen patients for psychological risk markers in clinical cardiology practice, as neither this information nor a proxy is available from the patients' medical records. The identification of this subset of high-risk patients would allow further intervention including optimisation of medical treatment but also adjunctive intervention of a psychosocial and behavioural nature. Accordingly, in a recent advisory the American Heart Association recommended that patients with heart disease be screened standardly for depression [28]. However, this recommendation has led to an ardent debate in the scientific community, since we do not know whether early screening and detection leads to improved clinical outcomes [29, 30]. Irrespectively, depression deserves treatment in its own right due to its influence on quality of life, patient well-being, and compliance, with standardised and validated screening tools being available as are treatment options to reduce the burden of depression [29].

\section{Screening for psychological morbidity}

In order to screen cardiac patients for psychological factors in a standardised and valid fashion, it is important to use validated and reliable instruments. This not only requires knowledge of test development but also knowledge of the procedures used to adapt into Dutch existing instruments that were developed abroad, both of which form part of the expertise of medical and clinical psychologists. Validation of instruments in the Dutch setting developed in another language is necessary, as there may be cross-cultural differences such that a particular item in a scale may not be relevant in a different language and cultural setting, which might jeopardise the validity and reliability of the entire instrument. Among others, in the Erasmus MC, we have developed and/or validated the disease-specific instruments the Heart Patients Psychological Questionnaire (HPPQ) [4], the ICD Patient Concerns questionnaire [2], the Minnesota Living with Heart Failure Questionnaire [3], and the Peripheral Artery Questionnaire [31, 32]. These instruments do not tap all psychological factors that have been associated with increased risk of morbidity and mortality in cardiac patients independent of traditional biomedical risk factors.

The HPPQ - in Dutch known as the Medisch Psychologische Vragenlijst voor Hartpatiënten (MPVH) - is a diseasespecific measure that was developed in order to be able to identify cardiac patients with psychological morbidity at an early stage such that cardiologists can intervene and if warranted refer the patient to a psychologist or another mental health professional. The HPPQ comprises four subscales tapping into patient well-being, feelings of being disabled, despondency, and social inhibition. The scale was validated in a mixed cohort of 1649 cardiac patients.
Research has shown that feelings of being disabled assessed at the time of the index MI predict death 8-10 years post-MI and also morbidity and mortality 4 years post-PCI independent of traditional biomedical risk factors [33-35].

In 1998, the collaboration with Wijbenga and others led to the translation and validation of the Minnesota Living with Heart Failure Questionnaire in Dutch, enabling the identification of patients with heart failure with poor quality of life [3]. Poor quality of life, as assessed with the Minnesota Living with Heart Failure Questionnaire, has been shown to predict mortality in heart failure patients [25].

Similarly, in 2005 we adapted and validated the ICD Patient Concerns questionnaire (ICDC) to the Dutch setting [2], which was developed in the UK to tap patient concerns about the ICD giving a shock [36]. Recently, in a cohort of ICD patients from the EMC, we have shown that patient concerns, as assessed with the ICDC, predict mortality with the associated odds being 2-fold [20].

With these developments at least two goals can be reached. First, in the diagnosis and treatment of patients with heart disease, the cardiologist has the opportunity to use diseasespecific self-report questionnaires representing the patient perspective. Such screening allows for the early identification of patients at high risk for cardiovascular morbidity and mortality, but may also aid in clinical decision-making pointing to patients who may need more aggressive or adjunctive treatment [37]. Dependent on the patient's psychological profile, level of psychological morbidity, and health status, it may be necessary to refer the patient to a medical psychologist. This healthcare professional is knowledgeable about heart disease, the impact of treatment options (e.g. living with an ICD) on patients, but also how to treat psychological morbidity taking into account the patient's social situation (e.g. not having a partner), such that the intervention is tailored to the individual. Due to the possibility of early intervention, this is not only likely to improve patient care but also survival. Second, it makes for a more complete and holistic approach to the clinical management of patients with heart disease. With the information provided by the questionnaires completed by patients, the cardiologist will have a better understanding of the psychological profile of the patient, which is likely to enhance patient-doctor communication, patient satisfaction and perhaps even patient adherence with treatment advice. Psychological morbidity, such as depression, has been shown to reduce adherence to cardiac rehabilitation and lifestyle advice in cardiac patients [38].

\section{Cardiac rehabilitation}

The time when the benefits of cardiac rehabilitation still had to be proven is luckily in the past. Today healthcare professionals involved in the care and treatment of cardiac patients are 
increasingly recognising that an $\mathrm{MI}$, bypass operation, heart transplantation, or the receipt of one or multiple ICD shocks may be associated with psychological consequences. In 1975 this was not the case, and scepticism towards cardiac rehabilitation was pervasive across the country. Together with the various Rehabilitation Committees of the Dutch Heart Foundation, the Rotterdam rehabilitation programme Capri served as a pioneer to promote cardiac rehabilitation. Scientific publications on the usefulness and effect of rehabilitation led to further evolvement of cardiac rehabilitation programmes $[7,39,40]$. Today's cardiac rehabilitation comprises a series of modules, including physical training, stress management, smoking cessation, dietary advice, and relaxation therapy that are targeted towards the needs of the individual patient. Following an acute cardiac event, cardiac patients today have the possibility of receiving professional assistance that is geared towards increasing physical activity and exercise tolerance, dealing with feelings of anxiety and depression, activating social support, and promoting social re-integration [41]. This is a far cry from what was available in 1975. Nevertheless, we are not quite there yet. So far, the assumption has been that one size fits all, while there is an indication that subsets of patients, such as women, older patients, and depressed patients, may warrant specialised and more individually tailored cardiac rehabilitation [42]. Moreover, there is a great disparity in the percentage of patients attending cardiac rehabilitation across Europe and a large number of patients who do not meet the lifestyle targets set out for cardiovascular disease prevention [43].

\section{Teaching}

Interview techniques and patient-doctor communication are, in our experience, not topics that the average cardiologist tends to consciously think about on a daily basis. Nevertheless, patient complaints lodged with the complaints committee of hospitals tend to a great extent to be attributable to poor patient-doctor communication, commonly leaving the patient with a feeling of not being listened to, misunderstood, and even mistreated. In order to enhance the quality of the consultation between patient and cardiologist, in the Erasmus MC at least one conversation between the intern and the patient is recorded on camera during the intern's training and is discussed with a psychologist (the first author). The intern will learn about the basic do's and don'ts of conversational techniques. Don'ts include starting the consult with a detailed cardiac history (usually serves to make the intern feel at ease), using medical terminology unnecessarily, posing suggestive questions, forcing a change in lifestyle (forcing does not help), displaying no empathy in situations that are difficult to the patient, writing down too much or looking at the computer screen instead of maintaining the relation with the patient by means of eye contact, forgetting to ask the patient if he has any further questions or if something is not clear at the end of the consult. When looking at the recording together with the psychologist, the intern is usually worried about potential criticism. However, it helps to say that the consult with the psychologist is meant as a learning opportunity and nothing else, and that the recording and what will be discussed will remain confidential. This instils in the intern a feeling of being in a safe and protective setting, which in turn enhances openness and facilitates discussion, while providing a way to learn from one's own mistakes and the possibility of becoming a better doctor. Throughout his or her career - when dealing with patients - the cardiologist is faced with the challenge of keeping a balance between these softer sides of patient care and the more technical aspects of clinical cardiology.

\section{Patient care}

Perhaps the most important remaining question is whether patient care has improved as a result of the addition of a psychologist to the interdisciplinary team managing patients with heart disease? The answer to this question is not straightforward, but the presence of such expertise makes it possible for cardiologists and cardiovascular nurses to:

- Consult the psychologist if a patient is emotionally distraught while admitted in the unit and needs psychological counselling.

- Prior to discharge, refer the patient via the psychologist to a healthcare professional with the same expertise in the area where the patient lives.

- Provide more optimal after care in the outpatient clinic with a cardiac psychologist onboard who is knowledgeable not only about psychological issues but also the somatic condition, including the latest treatment possibilities in clinical cardiology and the potential impact of such treatments on the patient.

In addition, the expertise of the psychologist may exert its influence on patient care in more subtle and indirect ways that are not necessarily visible or consciously acknowledged in daily clinical practice. From that point of view all of the aspects discussed here are woven together and form more than the sum of their parts in terms of improving the quality of patient care (Fig. 1).

\section{Cardiac psychology—future challenges}

Despite the progress made in the field of cardiac psychology since the decision to employ a full-time psychologist at 
Fig. 1 The role of the psychologist in improving the quality of patient care

\section{Psychologist}

- Training of staff, e.g. in communication

- Development of self-report instruments to use in clinical research and practice

- Research in cardiac psychology

- Screening and diagnosing psychopathology

- Feedback to cardiologist / nurse that can be used in care of patient

- Provision of adequate and standardised psychological treatment to vulnerable and highrisk patients

- Referral to other appropriate mental health professionals the Department of Cardiology in the Erasmus MC 35 years ago, there are several imminent challenges that need clinical and scientific attention, which are outlined in Table 1.

In essence all of these challenges relate to the inclusion of the patient perspective (i.e., asking the patient to rate how he or she feels) in the care and management of patients with heart disease with the objective of enhancing the quality of care that we give to patients. The value of behavioural and psychological factors was recognised by the European Society of Cardiology guidelines on cardiovascular disease prevention in 2003 [46]. Continued efforts

Table 1 Challenges ahead for the field of cardiac psychology that may help enhance the quality of patient care

Challenge Rationale

- Incorporating screening for psychological risk markers and health status as part of standard clinical practice

- Development and improvement of disease-specific self-report questionnaires

- Implementation and fine-tuning of behavioural interventions

- Further enhancement of secondary prevention programmes, such as cardiac rehabilitation
- Psychological factors and health status predict prognosis independent of traditional biomedical risk factors $[20,25,44]$ and cannot be derived from other proxy measures available in clinical practice

- The incorporation of patient-reported health status in clinical practice can help in treatment decisionmaking [45] and health status can be used as a performance measure of the quality of care [37]

- In 2003, behavioural and psychological factors were introduced for the first time in the official European guidelines on cardiovascular disease prevention [46], but little has changed in clinical practice

- These measures aid to identify vulnerable and high-risk patients in clinical research and practice [29]

- Evidence from large-scale intervention trials targeting depression is mixed with respect to influencing prognosis [47]

- The assumption that one size fits all and that we are able to influence cardiovascular endpoints might be some of the explanations for the failure of these trials, with stepped collaborative care being more successful $[29,48]$

- Cardiac rehabilitation is an effective means to reduce morbidity and mortality

- However, there is an indication that one size fits all does not hold, with subsets of patients, such as women, older patients, and depressed patients, warranting specialised and more individually tailored cardiac rehabilitation [42]

- There is a great disparity in the percentage of patients attending cardiac rehabilitation across Europe [49] and a large number of patients who do not meet the lifestyle targets set out for cardiovascular disease prevention [43]

- Development of genetic counselling - Screening, waiting for and learning of the outcome may lead to distress in subsets of patients [50] programmes for patients and their - No such programmes are currently available for patients and their families at the cardiology department families with a risk of familiar heart disease 
need to be made to increase the incorporation of these psychosocial factors in clinical practice. For example, consider how a patient would feel if he/she had heart disease and knew that being depressed would influence prognosis, would that patient not want to be screened for depression similar to screening for 'traditional risk factors' such as blood pressure, cholesterol levels, and blood glucose levels? Ignorance may be bliss, but knowing about the patient's psychological risk profile would provide the opportunities for integrative interventions and care. Already 35 years ago, the importance of the psychological profile of the patient in recovery and disease progression was recognised; the time now seems ripe for implementing what we have learnt to optimise cardiovascular care, particularly in high-risk patients. The major challenge for the future lies in the implementation of early psychological screening and assessment of behavioural and emotional problems, and treatment of these problems in cardiac patients, in particular with respect to availability of the necessary infrastructure, logistics, and staff.

Acknowledgements We would like to thank Professor Dr. Felix Zijlstra, Professor Dr. Maarten Simoons, Dr. Liesbeth Utens - the Erasmus MC - and Professor dr. Willem Kop, CoRPS-Center of Research on Psychology in Somatic diseases, Tilburg University, for their helpful comments to a previous draft of this article.

Open Access This article is distributed under the terms of the Creative Commons Attribution Noncommercial License which permits any noncommercial use, distribution, and reproduction in any medium, provided the original author(s) and source are credited.

\section{References}

1. Guarneri E, Horrigan BJ, Pechura CM. The efficacy and cost effectiveness of integrative medicine: a review of the medical and corporate literature. Explore (NY). 2010;6:308-12.

2. Pedersen SS, van Domburg RT, Theuns DAMJ, et al. Concerns about the implantable cardioverter defibrillator: a determinant of anxiety and depressive symptoms independent of experienced shocks. Am Heart J. 2005;149:664-9.

3. Wijbenga JAM, Duivenvoorden HJ, Balk AHMM, et al. Quality of life in chronic heart failure. Validation of the Dutch version of the Minnesota Living with Heart Failure Questionnaire. Cardiologie. 1998;5:627-31.

4. Erdman RAM. Medisch psychologische vragenlijst voor hartpatiënten (MPVH). Lisse: Swets \& Zeitlinger; 1982.

5. Utens EM. Information provision for patients undergoing cardiac surgery: a randomized controlled clinical trial [Voorlichting aan hartchirurgische patienten: Een gerandomizeerd gecontroleerd interventie-onderzoek]. Rotterdam: Erasmus Medical Center; 1989.

6. Van der Vlugt MJ, Pedersen SS, Boersma E, et al. Early discharge of patients with acute myocardial infarction has no adverse psychological consequences. Coron Health Care. 2001;5:73-9.

7. Erdman RA, Duivenvoorden HJ, Verhage F, et al. Cardiac rehabilitation: a 5-year follow-up study of mental functioning, work resumption, smoking habits and sports activities. Ned Tijdschr Geneeskd. 1984;128:846-51.
8. Serlie AW, Erdman RA, Passchier J, et al. Psychological aspects of non-cardiac chest pain. Psychother Psychosom. 1995;64:62-73.

9. van Berkel TF, Boersma H, Roos-Hesselink JW, et al. Impact of smoking cessation and smoking interventions in patients with coronary heart disease. Eur Heart J. 1999;20:1773-82.

10. Utens EM, Verhulst FC, Erdman RA, et al. Psychosocial functioning of young adults after surgical correction for congenital heart disease in childhood: a follow-up study. J Psychosom Res. 1994;38:745-58.

11. Bleeker JK, Simoons ML, Erdman RA, et al. Patient and doctor delay in acute myocardial infarction: a study in Rotterdam, The Netherlands. Br J Gen Pract. 1995;45:181-4.

12. Appels A, Bar F, van der Pol G, et al. Effects of treating exhaustion in angioplasty patients on new coronary events: results of the randomized Exhaustion Intervention Trial (EXIT). Psychosom Med. 2005;67:217-23.

13. Pedersen SS, Holkamp PG, Caliskan K, et al. Type D personality is associated with impaired health-related quality of life 7 years following heart transplantation. J Psychosom Res. 2006;61:7915.

14. Pedersen SS, Spek V, Theuns DA, et al. Rationale and design of WEBCARE: a randomized, controlled, web-based behavioral intervention trial in cardioverter-defibrillator patients to reduce anxiety and device concerns and enhance quality of life. Trials. 2009; 10:120.

15. Pedersen SS, den Broek KC, Theuns DAMJ, et al. Risk of chronic anxiety in implantable defibrillator patients: a multi-center study. Int J Cardiol. 2009;00.

16. Smolderen KG, Hoeks SE, Pedersen SS, et al. Lower-leg symptoms in peripheral arterial disease are associated with anxiety, depression, and anhedonia. Vasc Med. 2009;14:297304.

17. Pedersen SS, Van den Berg M, Erdman RAM, et al. Increased anxiety in partners of patients with a cardioverter-defibrillator: the role of indication for ICD therapy, shocks and personality. Pacing Clin Electrophysiol. 2009;32:184-92.

18. Pedersen SS, van Domburg RT, Theuns DA, et al. Type D personality is associated with increased anxiety and depressive symptoms in patients with an implantable cardioverter defibrillator and their partners. Psychosom Med. 2004;66:714-9.

19. Pedersen SS, Lemos PA, van Vooren PR, et al. Type D personality predicts death or myocardial infarction after bare metal stent or sirolimus-eluting stent implantation: a Rapamycin-Eluting Stent Evaluated at Rotterdam Cardiology Hospital (RESEARCH) registry substudy. J Am Coll Cardiol. 2004;44:997-1001.

20. Pedersen SS, van den Broek KC, Erdman RAM, et al. Pre implantation ICD concerns and Type D personality increase the risk of mortality in patients with an implantable cardioverter defibrillator. Europace. 2010;12:1446-52.

21. Utens EM, Verhulst FC, Meijboom FJ, et al. Behavioural and emotional problems in children and adolescents with congenital heart disease. Psychol Med. 1993;23:415-24.

22. van Rijen EH, Utens EM, Roos-Hesselink JW, et al. Longitudinal development of psychopathology in an adult congenital heart disease cohort. Int J Cardiol. 2005;99:315-23.

23. Pedersen SS, Denollet J, de Jonge P, et al. Brief depression screening with the PHQ-2 associated with prognosis following percutaneous coronary intervention with paclitaxel-eluting stenting. J Gen Intern Med. 2009;24:1037-42.

24. Pedersen SS, Kupper HM, Denollet J. Psychological factors and heart disease. In: Camm J, Lüscher T, Serruys PW, editors. ESC textbook of cardiovascular medicine. 2nd ed. Oxford: Oxford University Press; 2009.

25. Mommersteeg PM, Denollet J, Spertus JA, et al. Health status as a risk factor in cardiovascular disease: a systematic review of current evidence. Am Heart J. 2009;157:208-18. 
26. Dickens C, McGowan L, Percival C, et al. New onset depression following myocardial infarction predicts cardiac mortality. Psychosom Med. 2008;70:450-5.

27. Nicholson A, Kuper H, Hemingway H. Depression as an aetiologic and prognostic factor in coronary heart disease: a meta-analysis of 6362 events among 146538 participants in 54 observational studies. Eur Heart J. 2006;27:2763-74.

28. Lichtman JH, Bigger JT Jr, Blumenthal JA, et al. Depression and CORONARY HEART DISEASE. Recommendations for Screening, Referral, and Treatment. A Science Advisory From the American Heart Association Prevention Committee of the Council on Cardiovascular Nursing, Council on Clinical Cardiology, Council on Epidemiology and Prevention, and Interdisciplinary Council on Quality of Care and Outcomes Research. Circulation. 2008.

29. Whooley MA. To screen or not to screen? Depression in patients with cardiovascular disease. J Am Coll Cardiol. 2009;54:891-3.

30. Davidson KW, Korin MR. Depression and cardiovascular disease: selected findings, controversies, and clinical implications from 2009. Cleve Clin J Med. 2010;77 Suppl 3:S20-6.

31. Hoeks SE, Smolderen KG, et al. Clinical validity of a diseasespecific health status questionnaire: the peripheral artery questionnaire. J Vasc Surg. 2009;49:371-7.

32. Smolderen KG, Hoeks SE, Aquarius AE, et al. Further validation of the peripheral artery questionnaire: results from a peripheral vascular surgery survey in the Netherlands. Eur J Vasc Endovasc Surg. 2008;36:582-91.

33. van der Vlugt MJ, van Domburg RT, Pedersen SS, et al. Feelings of being disabled as a risk factor for mortality up to 8 years after acute myocardial infarction. J Psychosom Res. 2005;59:247-53.

34. Plevier CM, Mooy JM, Marang-Van de Mheen PJ, et al. Persistent impaired emotional functioning in survivors of a myocardial infarction? Qual Life Res. 2001;10:123-32.

35. Simsek C, Pedersen SS, van Gestel YR, et al. Feelings of being disabled as a prognostic factor for mortality in the drug-eluting stent era. J Psychosom Res. 2009;67:85-91.

36. Frizelle DJ, Lewin B, Kaye G, et al. Development of a measure of the concerns held by people with implanted cardioverter defibrillators: the ICDC. Br J Health Psychol. 2006;11:293-301.

37. Spertus JA. Evolving applications for patient-centered health status measures. Circulation. 2008;118:2103-10.

38. McGrady A, McGinnis R, Badenhop D, et al. Effects of depression and anxiety on adherence to cardiac rehabilitation. J Cardiopulm Rehabil Prev. 2009;29:358-64.

39. Uniken Venema-van Uden MM, Zoeteweij MW, Erdman RA, et al. Medical, social and psychological recovery after cardiac rehabilitation. J Psychosom Res. 1989;33:651-6.
40. Pelle AJ, Erdman RA, van Domburg RT, et al. Type D patients report poorer health status prior to and after cardiac rehabilitation compared with non-type D patients. Ann Behav Med. 2008;36:167-75.

41. Corra U, Piepoli MF, Carre F, et al. Secondary prevention through cardiac rehabilitation: physical activity counselling and exercise training: key components of the position paper from the Cardiac Rehabilitation Section of the European Association of Cardiovascular Prevention and Rehabilitation. Eur Heart J. 2010;31:196774.

42. Beckie TM, Beckstead JW, Schocken DD, et al. The effects of a tailored cardiac rehabilitation program on depressive symptoms in women: a randomized clinical trial. Int J Nurs Stud. In Press.

43. Kotseva K, Wood D, De Backer G, et al. EUROASPIRE III: a survey on the lifestyle, risk factors and use of cardioprotective drug therapies in coronary patients from 22 European countries. Eur J Cardiovasc Prev Rehabil. 2009;16:121-37.

44. Frasure-Smith N, Lesperance F. Depression and cardiac risk: present status and future directions. Heart. 2010;96:173-6.

45. Weintraub WS, Spertus JA, Kolm P, et al. Effect of PCI on quality of life in patients with stable coronary disease. N Engl J Med. 2008;359:677-87.

46. De Backer G, Ambrosioni E, Borch-Johnsen K, et al. European guidelines on cardiovascular disease prevention in clinical practice: third joint task force of European and other societies on cardiovascular disease prevention in clinical practice (constituted by representatives of eight societies and by invited experts). Eur J Cardiovasc Prev Rehabil. 2003;10:S1-10.

47. Berkman LF, Blumenthal J, Burg M, et al. Effects of treating depression and low perceived social support on clinical events after myocardial infarction: the Enhancing Recovery in Coronary Heart Disease Patients (ENRICHD) randomized trial. Jama. 2003;289:3106-16.

48. Rollman BL, Belnap BH, LeMenager MS, et al. The Bypassing the Blues treatment protocol: stepped collaborative care for treating post-CABG depression. Psychosom Med. 2009;71:21730.

49. Cooney MT, Storey S, Taylor L, et al. EUROASPIRE (European Action on Secondary Prevention through Intervention to Reduce Events) III-a comparison of Irish and European results. Ir Med J. 2009;102:113-6.

50. Hendriks KS, Hendriks MM, Birnie E, et al. Familial disease with a risk of sudden death: a longitudinal study of the psychological consequences of predictive testing for long QT syndrome. Heart Rhythm. 2008;5:719-24. 